\title{
Strong and Weak Novelty and Familiarity
}

\author{
Cleo Condoravdi
}

CSLI, Stanford University

\section{Introduction}

In the novelty/familiarity theory of indefinite and definite NP's that Heim (1982) develops, there is a one-to-one correspondence between the definiteness of an NP and the felicity conditions it is associated with. ${ }^{1}$ Two types of felicity conditions are associated with definite and indefinite NP's, an index condition and a descriptive content condition, and taken together they provide necessary and sufficient conditions for definiteness and indefiniteness.

In this paper I will argue that the felicity conditions associated with definites and indefinites vary both within a language and cross-linguistically. I will propose that the variation observed can be captured by distinguishing between strong and weak novelty and strong and weak familiarity. Strong novelty, corresponding to Heim's novelty, is construed as association with novelty conditions for the index and the descriptive content. Weak novelty is construed as association with a novelty condition for the index. Strong familiarity, corresponding to Heim's familiarity, is construed as association with familiarity conditions for the index and the descriptive content. Weak familiarity is construed as association with a familiarity condition for the descriptive content.

The evidence for the distinction between strong and weak novelty comes from two sources: (i) the existence of indefinite NP's which may presuppose their descriptive content, (ii) the existence of indefinite NP's which require the non-entailment of their descriptive content. Bare plurals in English exemplify the former type, and singular indefinites the latter. Similarly, the evidence for the distinction between strong and weak familiarity comes from two sources: (i) the existence of definite NP's which may be associated with a novel index, (ii) the existence of definite NP's which require that their index be familiar. Greek definite plurals exemplify the former type, and English definites the latter.

\section{The Functional Reading of Bare Plurals}

In this section I will establish that English bare plurals exhibit a universal reading which arises both with individual-level and stage-level predicates and cannot be straightforwardly attributed to the presence of a quantifier. The reading is tied to a presupposition of existence of a special kind and arises in contexts which entail existence of that sort. I call this reading 'the functional

${ }^{1}$ Thanks to Tony Davis, Donka Farkas, Mark Gawron, Bill Ladusaw, Louise McNally, Chris Piñon and Sandro Zucchi for very useful discussions and for their comments on oral presentations or previous versions of the paper. 
reading' since, as will be shown in section 4, a contextually salient function is implicated in its analysis.

\subsection{The Indefiniteness Analysis of Bare Plurals}

In the analysis of bare plurals as indefinite NP's, proposed by Krifka (1987) and Wilkinson (1988) and based on the treatment of indefinites in Kamp (1981) and Heim (1982), one type of genericity is reduced to the presence of an appropriate operator. The bifurcation in the readings of bare plurals noted by Carlson (1977) is a property shared by all indefinite NP's. The generic reading of singular and plural indefinites is a quantificational reading, arising when their corresponding variable is bound by a generic operator. The plural indefinite in (1a) and the singular indefinite in (1b) are analyzed as contributing a variable in the restriction of the implicit generic operator $G$, as in (2a). In (1c), on the other hand, there is no operator and the indefinite is caught by existential closure, as in (2b).

(1) a. Whales are mammals.

b. A whale is a mammal.

c. Whales are roaming the coast.
a. $\left(G_{x}:\right.$ whale $\left.(x)\right)$ mammal $(x)$
b. $\exists_{x}$ (whale $(x)$ \& roam-the-coast $\left.(x)\right)$

The generic operator, as argued by Krifka (1987, 1988, 1990), has two properties that will play a role in the discussion to follow: it is adverbial and it has a modal dimension. Since the determination of the modal dimension is heavily context dependent the multiple ambiguity that we detect with generic adverbial quantifiers can be explained away if we take into account the context dependency of their modal base and ordering source (Kratzer 1981; Heim 1982). The modal dimension of the generic operator also accounts for Dahl's (1975) observation that indefinite NP's are associated with a non-accidental generalization reading, under the assumption that an implicit generic operator is present, for example, in (3a) and (3b) but not in (3c).

(3) a. A member of this club does not drink whisky.

b. Members of this club do not drink whisky.

c. The members of this club do not drink whisky.

In what follows, I will adopt the analysis of bare plurals as indefinites but will show that besides their expected existential and generic readings bare plurals also have a reading in which they neither assert existence nor are bound by a quantifier. 


\subsection{Functional Reading with Individual-Level Predicates}

A prediction of the standard indefiniteness analysis is that the universal reading of bare plurals arises only in quantificational contexts. A universal reading, however, arises in a wider range of contexts than those that can be uncontroversially assumed to be quantificational. ${ }^{2}$ Consider (4a) and three possible continuations, (4b) - (4d), and note that (4b) appears synonymous with (4c), not (4d). (4b), unlike (4d), does not make an existential assertion and like (4c) it seems to presuppose the existence of students in the actual world.

(4) a. In 1985 there was a ghost haunting the campus.

b. Students were aware of this fact/the danger.

c. The students were aware of this fact/the danger.

d. There were students who were aware of this fact/the danger.

That the bare plural in (4b) lacks an existential reading is not surprising given that the predicate is individual-level. But is the universal reading due to the presence of an implicit generic operator? If there is such an operator, then it must be distinct from the one commonly assumed to be present in standard cases of generic quantification. To begin with, there is no non-trivial modal dimension to the operator: (4b) expresses an actual and, moreover, accidental generalization.

We might say that the operator is associated with a totally realistic modal base and a trivial ordering source, ${ }^{3}$ and that there are additional contextual restrictions limiting the domain of quantification to the students on the campus in 1985 during the ghost's appearance. On that analysis, (4b) would involve the quantificational structure in (5a) and it would end up expressing an actual generalization because the modal base would be determined by the context to be totally realistic and the ordering source trivial.

a. $\left(G_{x}\right.$ : student $\left.(x) \& C R(x)\right)$ be-aware $(x, p)^{4}$

b. (4b) is true in $w$ relative to a totally realistic modal base $R_{w}$ and a trivial ordering source $\leq_{w}$ iff for every $x$ such that student $(x) \&$ $\operatorname{CR}(x)$ is true in $w$ be-aware $(x, p)$ is also true in $w$.

\footnotetext{
${ }^{2} \mathrm{~A}$ more accurate description of the reading would be 'quasi-universal' given that exceptions do not suffice to render the generalization expressed false. In what follows, the term 'universal' is to be understood with this caveat.

${ }^{3}$ A totally realistic modal base is one which contains only the actual world, i.e., for all $w_{1}, w_{1} \in R_{w}$ iff $w_{1}=w$. A trivial ordering source is such that $w_{1} \leq w$ for any $w_{1}$ and $w$.

${ }^{4} \mathrm{CR}$ is a cover designation for the additional contextual restrictions. For the sake of conereteness, I have given the predicate be aware a proposition as its second argument but will not be concerned here with how the content of the propositional argument is construed.
} 
Such an analysis, quite apart from raising the question of whether we can in general use the implicit generic operator with a totally realistic modal base and a trivial ordering source to make non-generic universal statements, would not be sufficient as there remain two major problems. First, in exactly the same context as that of (4b), the singular indefinite has only an existential reading (consider (6)), hence the operator must somehow be prohibited from binding a variable contributed by a singular indefinite.

\section{(6) a. In 1985 there was a ghost haunting the campus. \\ b. A student was aware of the danger.}

Second, not any contextual restriction is possible. Specifically, there are contexts which provide extra information that could in principle constitute a further restriction on the domain of quantification but cannot be added to the restriction of the implicit operator. (7d) still expresses the same generalization as $(4 \mathrm{~b})$ in the context of $(7 \mathrm{a})$ and $(7 \mathrm{~b})$, not the more contextually restricted one corresponding to 'every student in this dormitory'. The overt nominal quantifier in (7c), on the other hand, accepts the extra contextual restriction.
a. There is a ghost haunting the campus.
b. There are 500 students in this dormitory.
c. Every student is aware of the danger.
d. Students are aware of the danger.

Similarly, in a deictic context, like that of $(8)$, the bare plural receives the same reading as (4b), not the more contextually restricted one picking out the perceptually salient students.

(8) Context: We know that there is a ghost haunting the campus. We are standing in front of the library and we can both see several students.

Students are afraid to enter the library.

Moreover, Krifka (1987) has argued on the basis of examples like (9) that nominal quantifiers are easily amenable to contextual restrictions (consider (9b)) while adverbial quantifiers and the implicit generic operator are not, at least with respect to individuals (consider (9c) and (9d)).

(9) a. (Out of the blue:) Every lion has a mane. (non-restricted)

b. There are lions and tigers in the cage. Every lion has a mane. (restricted or non-restricted)

c. There are lions and tigers in the cage. A lion always has a mane. (non-restricted only) 
d. There are lions and tigers in the cage. A lion has a mane. (non-restricted only)

Now, if the operator responsible for the universal reading of the bare plural in (4b) must accept contextual restrictions, it follows that (10b), as opposed to (10a) or (9d), must be ambiguous between a non-restricted and a restricted reading. The non-restricted reading would be due to the regular implicit generic operator, the restricted reading to the newly postulated implicit operator. However, only the non-restricted reading is available for both (10a) and $(10 \mathrm{~b})$.

(10) a. There are lions and tigers in the cage. Lions always have a mane.

b. There are lions and tigers in the cage. Lions have a mane.

To summarize so far: if we assume the presence of an operator, (i) we must explain why it cannot bind the singular indefinite, (ii) we must spell out the conditions for admissible contextual restrictions on the domain of quantification.

\subsection{Functional Reading with Contextually Restricted Adverbials}

Bare plurals can co-occur with certain contextually restricted proportional adverbs of quantification which presuppose the existence of the group forming the basis of the proportion and whose atomic parts they quantify over. The interaction of bare plurals with such adverbs demonstrates that the constraints on the selection of appropriate contextual restrictions are not determined entirely by the quantifier but depend on the indefinite NP as well. Therefore, even if we assimilated the special implicit operator to these adverbs, we would still have to account for the selective affinity of bare plurals with plural definite NP's.

The bare plural in (11b), like the plural definite in (11c) and in contrast to the singular indefinite in (11d) or the plural indefinite in (11e), is compatible with contextually restricted proportional adverbs of quantification. The only possible reading for (11d) and (1le) is one in which mostly/for the most part are predicate modifiers specifying the degree of awareness. ${ }^{5}$ Such a reading is excluded in (11f) because of the syntactic position of the adverb, hence (11f) is unconditionally unacceptable.

(11) a. There is a ghost haunting the campus.

b. Students are mostly/for the most part aware of the danger.

c. The students are mostly/for the most part aware of the danger.

d. (\#) A student is mostly/for the most part aware of the danger.

\footnotetext{
${ }^{5}$ The (\#) notation is meant to indicate that the sentences are unacceptable on the quan-
} tificational reading for the adverbial and acceptable on the predicate modifier reading. 
e. (\#) Some students are mostly/for the most part aware of the danger.

f. \# A student/Some students for the most part is/are aware of the danger.

g. The students/Students for the most part are aware of the danger.

The pattern in (11) shows that the distribution and interpretation of the adverbials is not just a matter of the plurality of the accompanying NP, nor a matter of definiteness alone. The crucial factor for the felicity of (11b) and (11c) is whether the previous context entails the existence of a group of students which is to form the basis of the proportion for the adverbial quantifier. If (12) is the LF representation for (11b) and (11c), students $(X)$ and $\mathrm{CR}(X)$ constitute presupposed information in the restriction of the quantifier. ${ }^{6}$

(12) (Mostly $: x \leq_{a t} X$ \& students $(X) \& C R(X)$ ) be-aware $(x, p)$

The question is what kind of information should be entailed for the definite NP and for the bare plural NP and what kinds of contexts entail it. In contexts mirroring those of (7), (8) and (10) contextual restrictions for the bare plural are again impossible. Consider (13), where only the non-contextually restricted reading is possible for the bare plural - giving rise to falsity, in fact - while the contextually restricted reading is present for the definite NP.

(13) a. There are lions and tigers in this cage.

b. The lions are mostly/for the most part old.

c. Lions are mostly/for the most part old.

In short, if we were to assume that the non-generic implicit operator is a proportional adverb of quantification, we could account for its incompatibility with the singular indefinite but we would still have to specify what the right entailments of existence are and which contexts give rise to them.

\subsection{Functional Reading in Quantified Contexts}

The universal reading of bare plurals arises in overtly quantified contexts as well and the presupposition of existence shows the expected presupposition projection effects.

\subsubsection{Adverbs of Quantification: Dependent Reading}

Consider (14). If we analyze (14b) as in (15a), then the variable bound by the adverb of quantification must pick out the maximal collection of students in each case, otherwise we would run into the proportion problem. For example,

\footnotetext{
${ }^{6}$ That these are presupposed, as opposed to simply introduced in the restriction of the quantifier, can be seen by the behavior of the plural indefinite some students.
} 
if there have been four such appearances of a ghost, and during one of them the number of students happened to exceed the number of students of the other three occasions taken together, then according to (15a) (14b) should be true, whereas intuitively ( $14 \mathrm{~b})$ is judged to be false. Alternatively, if we quantify over situations, as in (15b), the situations must be individuated in such a way as to contain the maximal collection of students in each case. Or, if we assume that an implicit operator is also present, as in (15c) and (15d), we must ensure that it has narrow scope w.r.t. the adverb of quantification. Note that (15c) gives us the wrong reading for $(14 \mathrm{~b}){ }^{7}$

(14) a. Ghosts have occasionally haunted this campus.

b. Students were usually aware of the danger.

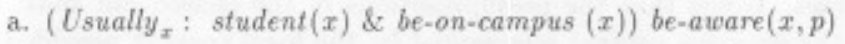

b. (Usually, : s : $\exists_{y, x}$ (ghost $(y)$ \& be-on-campus $(y, s)$ \& student $(x)$ \& be-on-campus $(x, s)))$ be-aware $(x, p)$

c. $\left(G_{x}^{\prime}\right.$ : student $(x) \&$ be-on-campus $\left.(x)\right)\left(\left(\right.\right.$ Usually, : s : $\exists_{y}($ ghost $(y)$ $\&$ be-on-campus $(y, s))$ ) be-aware $(x, p))$

d. (Usually $: s: \exists_{y}($ ghost $(y) \&$ be-on-campus $\left.(y, s))\right)\left(\left(G_{x}^{\prime}:\right.\right.$ student $(x)$ \& be-on-campus $(x, s)$ ) be-aware $(x, p))$
}

The effect that bare plurals have on the individuation of the domain of quantification shows that they can impose certain requirements on the context w.r.t. which they are evaluated. This is, in fact, what we would expect if the conclusion reached in section 2.3 is on the right track and if we have a sufficiently fine-grained conception of context.

\subsubsection{Projection of the Existential Presupposition}

In the consequent of a conditional, the singular indefinite may have an existential reading, as in (16b). In the same position, the bare plural in (16a) has only the universal reading. Moreover, (16a), but not (16b), seems to presuppose that there are students with connections in the police department in all campuses in the domain of quantification. This must be because of the existential presupposition associated with the bare plural.

(16) a. Usually, if a ghost is present on a campus, students with police connections are aware of the danger.

b. Usually, if a ghost is present on a campus, a student with police connections is aware of the danger.

\footnotetext{
${ }^{7}$ According to (15c), every student on the campus is such that he/she was aware of most appearances of a ghost.
} 
Let us first see that the existential presupposition associated with the bare plural on its special reading is projected in the usual fashion in conditional sentences. Indeed, (17a) and (17b) as a whole presuppose that there are students with connections in the police department. ${ }^{8}$

(17) a. If students with connections in the police department are aware of the danger, they will inform the rest.

b. If a ghost is present on the campus, students with police connections are aware of the danger.

Assuming the account of presupposition projection proposed by Karttunen (1974) and Heim (1983), the existential presupposition associated with the bare plural in the consequent of (16a) affects the domain of quantification as follows. Given that the presuppositions of the consequent must be entailed by the previous context augmented by the local context provided by the antecedent, the existence of students with connections in the police department must be entailed for each choice of campus and occasion of a ghost's presence on a campus. Therefore, we assume either that there are no campuses without students with police connections, or if such campuses exist, that they are not in the domain of quantification.

\subsection{Functional Reading with Stage-Level Predicates}

The universal reading of bare plurals also shows up with stage-level predicates, in purely episodic contexts. The sentences in (18) are ambiguous: on one reading, they are synonymous with the corresponding ones in (19), on the other, they are understood as involving the totality of the entities specified by the NP. On the latter reading, for example, (18a) is a statement about all (relevant) linguistic theories and (18b) is a promise about all (relevant) details.

(18) a. Linguistic theories have posited abstract representations.

b. Details will be presented tomorrow.

(19) a. There are linguistic theories that have posited abstract representations.

b. There are details that will be presented tomorrow.

Similarly, (20) can be understood either as an existential statement about some opponents and proponents of the approval, or as a statement involving

\footnotetext{
${ }^{8}$ The conditionals in (17) are meant to be one-case conditionals, so the implicit necessity operator (assumed to be present in all conditionals) is to be taken as having an epistemic modal base. Also, in (17b) the presupposition is inherited by the whole conditional under the assumption that the presence of a ghost makes no difference one way or another with respect to the existence of students with police connections on the campus.
} 
the totality of the opponents and proponents of the approval. Moreover, the totality effect associated with the second reading is independent of the kind of predication involved. Both readings allow for a distibutive or a collective predication.

(20) Although the odds still seem to favor Senate approval of Thomas, opponents redoubled their effort and tried to delay a floor vote on confirmation ...Proponents, in contrast, demanded a vote next week.

(San Francisco Chronicle, Sept. 28, 1991)

That the universal reading is present in purely episodic contexts is surprising and problematic for all existing theories of bare plurals and the individual/ stage-level contrast. Let us consider, for instance, the theory of Kratzer (1989) and Diesing (1990). On that theory, if a predicate is stage-level, it contains a davidsonian variable, and in order for an indefinite not to receive an existential reading it would have to be outside the domain of existential closure. More concretely, (21a) is the LF representation corresponding to the structure in which the indefinite has remained within the domain of existential closure; depending on the predicate, we can have a distributive or a collective reading. (21b) and (21c) are the LF representations corresponding to the structure in which the indefinite has moved outside the domain of existential closure.

a. (before-now $(l) \& \exists_{X}$ (proponents $(X)$ \& demand-vote $(X, l)$ ) (distributive and collective reading)

b. $\left(G_{x}^{\prime}\right.$ : proponent $(x) \&$ before-now $\left.(l)\right) \exists_{l^{\prime}}\left(l^{\prime} \leq l \&\right.$ demand-vote $\left.\left(x, l^{\prime}\right)\right)$

(distributive reading)

c. before-now $(l) \&$ proponents $(X) \& \exists$ (demand-vote $(X, l)$ ) (uninterpretable)

An indefinite outside the domain of existential closure must be bound by an operator; otherwise, the sentence would be uninterpretable since indefinites cannot be given a value by the context of use. ${ }^{9}$ Let us, in fact, assume that there is an operator with all the provisions needed to cover the problems discussed earlier. ${ }^{10}$ An operator, as in (21b), would give us the universal reading

\footnotetext{
9I the system of Heim (1982) in Chapter II, operator indexing makes reference to indefiniteness, there is text-level existential closure and the context of use is assumed to supply a value for any free variable (since only definites may end up as free variables). In the system of Kratzer (1989), by contrast, operators bind all free variables in their restriction, there is no text-level existential closure and, as a consequence, free variables must be discriminated as to whether they correspond to indefinites or not.

${ }^{10}$ For cases with no iterative reading we would, in addition, have to ensure that the operator binds only the variable of the indefinite and not the davidsonian variable. See the previous footnote for why this is a problem.
} 
but it would, in addition, force a distributive reading. Thus, an analysis along the lines of Kratzer and Diesing predicts that the existential reading occurs with either a distributive or a collective predication while the universal reading occurs only with a distributive predication. However, both (20) and (22), which contains a purely collective predicate, can be interpreted as involving a single group and a single eventuality. ${ }^{11}$

(22) Proponents met to discuss their strategy.

The crucial observation is that the universal reading is systematically related to a presupposition of existence. ${ }^{12}$ It is not a consequence of some pragmatic conversational implicatures. For example, (23) does not acquire a universal reading in a context in which I utter it while looking outside the window, having every reason to believe that all the dogs I can see are all the dogs tearing up my backyard, and in which the hearer is aware of that fact.

(23) Dogs are tearing up my back yard.

Nor is the universal reading an artifact of the interpretation of determinerless NP's since when the bare plural receives an existential interpretation and there is an assertion of existence, there is no totality effect present.

\subsection{Overview}

The issues raised by the facts we have considered so far are as follows.

[1] If a contextually restricted implicit operator is responsible for the universal reading of the bare plural in ( $4 \mathrm{~b})$, then the contextual restrictions cannot be supplied simply by the context of utterance. This was shown by the excluded readings of $(7 \mathrm{~d}),(8),(10 \mathrm{~b}),(13 \mathrm{c})$, and by the fact that in certain quantified contexts the implicit operator must have narrow scope w.r.t. another operator, like the adverb of quantification usually in (14).

[2] How can we characterize the presupposition of existence that is present? This is a problem we have to address regardless of whether we give an operator analysis for the bare plurals in (4b), (7d), (8), (14b) or not since the existential presupposition also has the effects witnessed in (11), (16a), (17), (18), (20), (22).

[3] If there is no operator, how is the bare plural interpreted?

[4] If we analyze the bare plural as a plain indefinite, then how does it differ from the singular indefinite or other plural indefinites $((6),(11 d-f),(16 b))$ and why does it appear to be in free variation with the corresponding definite in certain contexts $((4 \mathrm{c}),(11 \mathrm{c}))$ ? The definite in $(4 \mathrm{c})$ and $(11 \mathrm{c})$ must be felicitous by virtue of accommodation. But if both a definite and an indefinite NP are

\footnotetext{
${ }^{11} \mathrm{~A}$ similar argument can be made with respect to individual-level collective predicates.

${ }^{12}$ In Diesing's theory, while it is true that an indefinite presupposes existence iff it undergoes QR, there is no way to interpret QR'ed indefinites not bound by an operator.
} 
acceptable in precisely the same context and with the same semantic effect what does that indicate about their respective felicity conditions?

[5] On the other hand, we do not want the bare plural to be a disguised definite description of the usual sort either. Again (7d), (8), (10b) and (13c) constitute eviderice against such an approach. If we analyzed those instances of bare plurals as disguised definite descriptions, we would run into the same problem we did assuming an implicit operator; on the operator analysis we have to answer the question what kinds of contextual restrictions are acceptable, on the disguised definite description analysis the question what kinds of antecedents are acceptable. We are, however, better off with respect to quantificational contexts ${ }^{13}$ and the presupposition projection effects.

I will strike a balance by analyzing bare plurals as indefinite descriptions which always require a novel index but which can be felicitous in a wider range of contexts than standard indefinites. The universal reading which is associated with a presupposition of existence arises when the bare plural is evaluated w.r.t. a context entailing its descriptive content, in a sense to be made precise. I will cast the analysis within the file change theory of Heim (1982) but in order to allow for the possibility of indefinites which are felicitous w.r.t. contexts entailing their descriptive content certain revisions will have to be made.

\section{The Novelty/Familiarity Theory of Definite and Indefinite NP's}

In the file change theory, which underlies Heim's novelty/familiarity analysis of definites and indefinites, the interpretation of a given element is provided by specifying its file change potential. The file change potential is a function, possibly partial, from files to files, Files model semantic contexts and are construed as pairs consisting of a set of natural numbers, the domain of the file $\operatorname{Dom}(\mathrm{F})$, and a set of assignment function-possible world pairs, the satisfaction set of the file Sat(F). The felicity conditions an element may be associated with specify the conditions under which the function from files to files is defined. The felicity conditions associated with definite and indefinite NP's are covered by the Extended-Novelty-Familiarity-Condition (Heim 1982, 369-70).

(24) Extended-Novelty-Familiarity-Condition:

For $\phi$ to be felicitous w.r.t. a file $\mathrm{F}$, for every $\mathrm{NP}_{i}$ in $\phi$ it must be the case that:

a. if $N P_{i}$ is [-def], then $i \notin \operatorname{Dom}(F)$;

b. if $\mathrm{NP}_{i}$ is [+def], then $i \in \operatorname{Dom}(\mathrm{F})$ and if $\mathrm{NP}_{i}$ is a formula, $\mathrm{F}$ entails $N P_{i}$.

An NP is [+def] iff (a) its index is in the domain of the file, (b) its descriptive content is entailed by the file. The familiarity of the descriptive

\footnotetext{
${ }^{13}$ Like narrow-scope definites, bare plurals would be getting a dependent reading. See Heim (1982) for discussion of narrow-scope definites.
} 
content condition captures the intuition that definites presuppose their descriptive content. The two conditions jointly imply that in order for $\mathrm{NP}_{i}$ to be felicitous w.r.t. context $\mathrm{F}$ then $i \in \operatorname{Dom}(\mathrm{F})$ and, for all $\left\langle\mathrm{a}_{N}, w\right\rangle \in \operatorname{Sat}(\mathrm{F}), \mathrm{a}_{i}$ is $\overline{\mathrm{N}}$ in $w$ (taking $\overline{\mathrm{N}}$ to correspond to the common noun predicate of the NP).

An NP is [-def] iff (a) its index is not in the domain of the file, (b) its descriptive content is not entailed by the file. The novelty of the descriptive content condition captures the intuition that indefinites assert their descriptive content. The two conditions jointly imply that in order for $\mathrm{NP}_{i}$ to be felicitous w.r.t. context $\mathrm{F}$ then $i \notin \operatorname{Dom}(\mathrm{F})$ and there is some $\left\langle\mathrm{a}_{N}, w\right\rangle \in \operatorname{Sat}(\mathrm{F})$ such that $\mathrm{a}_{i}$ is not $\overline{\mathrm{N}}$ in $w,^{14}$

There is, however, no necessary logical connection between the index condition and the descriptive content condition. ${ }^{15}$ In Heim's system, the descriptive content condition for novelty is a consequence of the index condition by Condition B, a stipulated general condition on files, while for familiarity, the familiarity of the index follows from the descriptive content condition given Condition $\mathrm{B} .{ }^{16}$ Condition $\mathrm{B}$ ensures that a file does not cross-reference to nonexistent discourse referents: ${ }^{17}$ sequences in the satisfaction set of a file must agree exactly on the indices already in the domain of the file and can vary everywhere else. Formally, it is stated as in (25) (Heim 1982, 304).

(25) Condition B:

For every file $\mathrm{F}$, for every $\mathrm{n} \notin \operatorname{Dom}(\mathrm{F})$ : if $\mathrm{a}_{N}$ and $\mathrm{b}_{N}$ are two sequences that are alike except insofar as $\mathrm{a}_{n} \neq \mathrm{b}_{n}$, then $\mathrm{a}_{N} \in \mathrm{Sat}_{w}(\mathrm{~F})$ iff $\mathrm{b}_{N} \in \mathrm{Sat}_{w}(\mathrm{~F})$, for all worlds $w$.

With Condition B Heim gets the novelty of the descriptive content of an indefinite NP for free, given the novelty of its index, and can tie together the felicity conditions for the index and the descriptive content of a definite NP so that the relevant assignment functions assign the right kind of entity to the right index, namely the index corresponding to the referential index of the NP is assigned to an entity of which the predicate of the NP holds.

The intuitions captured this way are the following two equivalences: (a) an NP asserts existence iff it introduces a new discourse referent, (b) an NP

\footnotetext{
${ }^{14}$ This is actually not strong enough, as it would allow for a context in which all words contain individuals which are $\overline{\mathrm{N}}$; it could be strengthened so as not to depend on the assignment for the index of the NP, along the lines of fn.15. In any case, as we will see shortly, Heim does not need to specify a felicity condition requiring the non-entailment of descriptive content for indefinite NP's because of a general constraint she imposes on files.

${ }^{15}$ In principle, a file can entail, for example, that there is something that is a cat without having a fixed assignment for the index of the NP. Given that a file F entails a formula $\phi$ iff Sat $(F) \subset S a t(F+\phi)$, a file $F$ would entail the open formula ' $x$ is a cat' iff for every $\left(\mathrm{a}_{N}, w\right) \in \operatorname{Sat}(\mathbf{F})$ there is some $j$ such that $\mathrm{a}_{j}$ is a cat in $w$.

${ }^{16}$ This is actually true only for NP's with non-trivial descriptive content.

${ }^{17}$ Discourse referents correspond formally to indices in the domain.
} 
presupposes existence iff it is anaphoric on an already existing discourse referent. The evidence from the behavior of bare plurals discussed in section 2 argues that we must allow for NP's which presuppose existence but introduce a new discourse referent. Empirically, therefore, the biconditional in (a) fails in the leftward direction - if an NP introduces a new discourse referent, it is not necessarily the case that it asserts existence ${ }^{18}$ - and the biconditional in (b) fails in the rightward direction - if an NP presupposes existence, then it is not necessarily the case that it is anaphoric. ${ }^{19}$ At a somewhat more technical level, Condition B imposes the following restriction: no conditions involving individuals can be placed on worlds in the common ground except through discourse referents. This restriction we now have reason to reexamine, and are therefore forced to abandon Condition B.

If we allow for NP's to be associated with a single felicity condition, however, we can no longer express the entailment or non-entailment of the descriptive content of an NP in terms of F entailing or not entailing the NP (more accurately, a formula reconstructible from the NP). But then what exactly should a file entail for a given NP? As I will show in the next section, we have to appeal to the notion of a file entailing another file.

\section{Weak Novelty}

I propose that bare plurals are indefinites which are associated only with an index felicity condition. Consequently, they are felicitous both w.r.t. files that do not entail their descriptive content and w.r.t. files that do. In the former case, bare plurals have the range of interpretations standard indefinites do, in the latter, they acquire the special universal reading. Files of the latter type are restricted to come about only under certain circumstances.

Let $(26 \mathrm{a})$ and $(26 \mathrm{~b})$ be the LF representations of (4a) and (4b), respectively, and $\mathrm{F}$ the file obtained after the utterance of $(4 \mathrm{a})$.

$$
\begin{aligned}
& \text { a. ghost }\left(x_{m}\right) \& \text { campus }\left(x_{j}\right) \& \text { haunt }\left(x_{m}, x_{j}, x_{l}\right) \& \text { in- } 1985\left(x_{l}\right) \\
& \text { b. } \operatorname{student}\left(x_{i}\right) \& \text { be-aware }\left(x_{i}, p\right)
\end{aligned}
$$

Given that it is part of general background knowledge that campuses have students, we can assume the existence of a function $f^{\text {student }}$ which assigns to each campus in the universe of discourse the maximal collection of students in that campus, as in (27). ${ }^{20}$

(27) $f^{x t u d e n t}:\{x: x$ is a campus $\} \rightarrow\{Y: Y$ is the maximal collection of students on $x$ \}

\footnotetext{
${ }^{18}$ In other words, it does not assert existence w.r.t. all (felicitous) contexts.

${ }^{12}$ It is not anaphoric w.r.t. to all (felicitous) contexts.

${ }^{20}$ Contextually salient functions have been invoked for the analysis of pronouns (Cooper 1979 , Engdahl 1986, Heim 1990, Chierchia 1992, inter alia) and indefinite NP's with the modifier certain (Hintikka 1986).
} 
Given the existence of such a function, the file obtained after the utterance of (4a) may be incremented as in (28), whereby its domain remains unchanged and its satisfaction set is changed to include pairs whose worlds are such that some individual is the value $f^{\text {student }}$ assigns to the campus of (4a). ${ }^{21}$

(28) $\operatorname{Dom}\left(\mathrm{F}_{1}\right)=\operatorname{Dom}(\mathrm{F})$

$$
\operatorname{Sat}\left(\mathrm{F}_{1}\right)=\left\{\left\langle\mathrm{a}_{N}, w\right\rangle \in \operatorname{Sat}(\mathrm{F}): \exists k: k \notin \operatorname{Dom}(\mathrm{F}) \text { and } \mathrm{a}_{k}=f^{\text {student }}\left(\mathrm{a}_{j}\right) \text { in } w\right\}
$$

With this move we have ensured that $F_{1}$ contains the information, not contained in F, that some individual satisfies the descriptive content of the NP students for all worlds in the common ground. However, $\mathrm{F}_{1}$ does not entail student $\left(x_{i}\right)$ if $i \notin \operatorname{Dom}\left(\mathrm{F}_{1}\right)$ since the assignment to $i$ can be anything whatsoever.

If bare plurals require that their index be novel but can be felicitous with respect to contexts entailing their descriptive content, then the incrementation in (29), from $F_{1}$ to $F_{2}=F_{1}+(26 b)$, can be defined, as long as $i \notin D o m\left(F_{1}\right)$.

(29) $\operatorname{Dom}\left(\mathrm{F}_{2}\right)=\operatorname{Dom}\left(\mathrm{F}_{1}\right) \cup\{i\}$

$\operatorname{Sat}\left(\mathrm{F}_{2}\right)=\left\{\left\langle\mathrm{a}_{N}, w\right\rangle \in \operatorname{Sat}\left(\mathrm{F}_{1}\right): \mathrm{a}_{i}=f^{\text {student }}\left(\mathrm{a}_{j}\right)\right.$ and $\mathrm{a}_{i}$ is aware of the danger in $w$ \}

In a context entailing existence, the individuals to satisfy the uttered sentence have to be found amongst those whose existence has been established that way. The effect of the assertion of the indefinite is to fix the assignment for $i$, i.e., to introduce a new discourse referent. The novelty of the index accounts for why we do not get anaphoric readings with bare plurals, as shown by ( $7 \mathrm{~d}$ ), (8), (10b) and (13c). ${ }^{22}$

Note that we need to appeal to the existence of a salient function relating campuses and the maximal collections of their students for the interpretation of the definite in (4c). What we can informally characterize as the 'accommodation of the definite', amounts formally to the incrementation from $F$ to $F_{1}$ seen in $(30){ }^{23}$

\footnotetext{
${ }^{21}$ Conditions on worlds have to be formulated in terms of assignment functions but this does not mean that we are introducing discourse referents through the back door since we are not fixing the assignment for any particular index.

${ }^{22}$ The novelty of the index excludes presupposed coreference. If it so happens that the dormitory in (7) turns out to contain all the students on campus we will have accidental coreference. To exclude presupposed coreference and hence the anaphoric reading it suffices that some world in the common ground contains some individual that satisfies the descriptive content of the NP and is distinct from those individuals given as the value for indices in the domain and satisfying the descriptive content of the NP.

${ }^{23}$ The definite as well as the bare plural tolerate exceptions up to a point. I am assuming that there is a certain default structure in the construction of the sets which are the value of $f^{\text {gtsdent }}$. Individuals are assumed to be in that set only if they are not abnormal w.r.t. what is predicated of them. The operator analysis discussed in section 2 is no better off at accounting for the tolerance to exceptions since the operator needs a trivial modal dimension for independent reasons.
} 
(30) $\operatorname{Dom}\left(\mathrm{F}_{1}\right)=\operatorname{Dom}(\mathrm{F}) \cup\{i\}$

$\operatorname{Sat}\left(\mathrm{F}_{1}\right)=\left\{\left\langle\mathrm{a}_{N}, w\right\rangle \in \operatorname{Sat}(\mathrm{F}): \mathrm{a}_{i}=f^{\text {stwdent }}\left(\mathrm{a}_{j}\right)\right\}$

However, not any kind of function can be invoked in the incrementation of (28); if that were the case, there would be another source for the unwanted anaphoric reading in (7d), (8), (10b) and (13c). We must distinguish between saliency in the discourse context or the extralinguistic deictic context, on the one hand, and saliency arising from general background knowledge, on the other. At this point I must stipulate that only saliency of the latter type may give rise to the incrementation of the type seen in (28). ${ }^{24}$

For quantificational contexts, like that of (14), we must assume the existence of functions as in (31) mapping every campus and every occasion in which a ghost haunted that campus to the maximal collection of students in that campus on that occasion. The satisfaction set of the file incremented by (14b) is as in (32).

(31) $f^{\text {student }}:\{\langle x, s\rangle: x$ is a campus and $s$ a situation in which a ghost haunted $x\} \rightarrow\{Y: Y$ is the maximal collection of students on $x$ at $s\}$

(32) $\operatorname{Sat}(\mathrm{F}+(14 \mathrm{~b}))=\left\{\left\langle\mathrm{a}_{N}, w\right\rangle>\in \mathrm{Sat}\left(\mathrm{F}_{1}\right)\right.$ : for most $\mathrm{b}_{N}$ such that they agree with $a_{N}$ on the $\operatorname{Dom}(F)$ and $b_{l}$ is a situation $s$ in which there is a ghost on $\mathrm{a}_{j}\left(=\mathrm{b}_{j}\right)$ in $w$ and there is $\mathrm{c}_{N}$ such that it agrees with $\mathrm{b}_{N}$ on $\operatorname{Dom}(\mathrm{F})$ $U\{l\}$ and $c_{i}$ is the maximal collection of students on $a_{j}$ in $b_{f}$ in $w$ it is also the case that $c_{i}$ is aware of the danger in $w$ \}

Now, if bare plurals are felicitous with respect to contexts entailing their descriptive content, then the incrementation of the type exemplified by (28) is always allowed as long as the right conditions of saliency obtain. Hence we do not have to say anything special about why bare plurals exhibit the universal reading both with individual-level predicates and with stage-level predicates. I will leave as an open question what forces the incrementation in the presence of individual-level predicates and where exactly the presupposition of existence resides. A full answer to this question would have to include an analysis of individual-level predicates, a task which is largely independent of my concerns in this paper.

What I have assumed so far is that bare plurals in English differ from runof-the-mill indefinites in that they impose a weaker requirement on contexts to which they can be felicitously added; they only require that their index be novel with respect to the domain of the file. ${ }^{25}$ I propose that indefinites may be distinguished according to whether they are weakly or strongly novel. An

\footnotetext{
${ }^{24}$ This distinction has a precedent; as reported by Krifka (1990), it governs the choice of definite article in certain dialects of German and in Frisian.

${ }^{25}$ How is maximality guaranteed? So far I have built it directly into the analysis so as to make the formulation of certain things more straightforward. However, I do not believe it
} 
indefinite is WEAKLY NOVEL iff it is associated with an index felicity condition. An indefinite is STRONGLY NOVEL iff it is associated both with an index and a descriptive content condition. ${ }^{26}$ The index condition requires that the index not be in the domain of the file. The descriptive content condition states that a file $\mathrm{F}$ would be an admissible context for the addition of an indefinite NP if it does not entail the file obtained by incrementing F with the NP (see also Heim 1987, fn. 4).

(33) $\mathrm{F}_{1}=\mathrm{F}+\mathrm{NP} \mathrm{P}_{i}$, where $\mathrm{NP}_{i}$ is weakly novel, is defined only if $i \notin \operatorname{Dom}(\mathrm{F})$

(34) $\mathrm{F}_{1}=\mathrm{F}+\mathrm{NP}$, where $\mathrm{NP}_{i}$ is strongly novel, is defined only if both (a) and (b) hold:

a. $i \notin \operatorname{Dom}(\mathrm{F})$;

b. $\mathrm{F}$ does not entail $\mathrm{F}+\mathrm{NP}_{i}$ (i.e., there is $\left\langle\mathrm{a}_{N}, w\right) \in \mathrm{Sat}(\mathrm{F})$ such that for all $\mathrm{b}_{N}$ agreeing with $\mathrm{a}_{N}$ for all $\left.j \in \operatorname{Dom}(\mathrm{F})\left(\mathrm{b}_{N}, w\right\rangle \notin \operatorname{Sat}\left(\mathrm{F}+\mathrm{NP}_{i}\right)\right)$.

The condition in (34b) requires that there be some world in the world set of the file which contains no individuals which satisfy the descriptive content of the NP. Requiring simply the non-entailment of $\mathrm{NP}_{i}$ would be too weak since as we saw w.r.t. (28) $\mathrm{F}_{1}$ does not entail $\mathrm{NP}_{i}$ but it does entail $\mathrm{F}+\mathrm{NP}_{i}$. On the other hand, if $\mathrm{F}$ does not entail $\mathrm{F}+\mathrm{NP}_{i}$, then it does not entail $\mathrm{NP}_{i}$ either.

Given this characterization for the entailment of the descriptive content of an NP, a weakly novel NP would be strong, in the familiar sense of Milsark (1974), in contexts entailing its descriptive content; this is, in fact, what excludes the universal reading of the bare plural in there-sentences. See Heim

should be made part of the semantics of the bare plural. For example, here's an alternative, where maximality arises as a by-product. Instead of the function in (27), assume we invoke the function in (a), instead of the incrementation in (28), we have the incrementation in (b). where $\chi$ is a choice function (a choice function $\chi$ is such that $\chi(A) \in A$, for any nonempty set A), and instead of the incrementation in (29), we have the incrementation in (c). This is the strategy that Gawron, Nerbonne \& Peters (1991) and Chierchia (1992) adopt to get maximality for E-type pronouns.

a. fotudent: $\{x: z$ is a campus $\} \rightarrow\{Y: Y$ is the set of all sets of students on $x\}$

b. $\operatorname{Sat}\left(\mathrm{F}_{1}\right)=\left\{\left(\mathrm{a}_{N}, w\right\rangle \in \operatorname{Sat}(\mathrm{F}): \exists k: k \notin \operatorname{Dom}(\mathrm{F})\right.$ and $\mathrm{a}_{k}=\chi\left(f^{\text {student }}\left(\mathrm{a}_{j}\right)\right)$ in $\left.w\right\}$

c. $\operatorname{Sat}\left(\mathrm{F}_{2}\right)=\left\{\left(\mathrm{a}_{N}, w\right) \in \operatorname{Sat}\left(\mathrm{F}_{1}\right): \mathrm{a}_{i}=\chi\left(f^{n t u d e n t}\left(\mathrm{a}_{j}\right)\right)\right.$ and $\mathrm{a}_{i}$ is aware of the danger in $\left.w\right\}$

Maximality would arise under the assumption that the truth or falsity of what is said should not depend on the choice made for the value of $\chi$, so the appropriate value for $\chi$ in this case is one that picks out the maximal collection of students. There are alternative ways of working this out but I cannot pursue them here.

${ }^{26} \mathrm{Can}$ there be NP's with diverging felicity conditions w.r.t. their index and descriptive content? Such NP's are conceivable, at least for certain combinations of felicity conditions (e.g., a condition requiring novelty for the index and one requiring familiarity for the descriptive content); whether they actually exist is an open question. 
(1987) for a formulation of weakness and strength applying directly to NP's rather than determiners in the framework of file change semantics.

\section{Weak Familiarity}

Now that we have relativized indefiniteness and novelty, the question arises whether definiteness and familiarity should be relativized as well and whether this is to be done along similar lines. What I have said so far should lead us to expect that the answer is yes. If an element can have a presupposition of existence without necessarily being anaphoric (that is without being anaphoric with respect to every context), then we would expect to find elements whose descriptive content must be familiar and which are felicitous both in contexts in which their index is familiar and in contexts in which their index is novel. In this section I show that definite plural NP's in Greek are precisely of that type. The crucial contexts in which we can straightforwardly tease apart definites with a novel index and definites with a familiar index are quantificational contexts. ${ }^{27}$

The distribution and interpretation of plural definites and bare plural indefinites in Greek parallels only partly that of their English equivalent. In non-quantificational contexts bare plural indefinite NP's have an existential reading and assert their descriptive content, as in (35a), and definite NP's have an anaphoric reading and pressupose their descriptive content, as in (35b). ${ }^{28}$

\section{a. Falenes trigirizoun stis aktes. \\ Whales are-roaming in-the coasts \\ 'Whales are roaming the coast.'}

b. I falenes trigirizoun stis aktes.

the whales are-roaming in-the coasts

'The whales are roaming the coast.'

A striking property of definite plural NP's in Greek is that they can be bound directly by quantifiers. In fact, in environments of standard generic quantification, as in (36), the definite is acceptable, the bare plural indefinite is unacceptable.

a. I falenes ine thilastika. the whales are mammals

'Whales are mammals.'

b. *Falenes ine thilastika.

whales are mammals

'Whales are mammals.'

\footnotetext{
${ }^{27}$ Already in Heim (1982) narrow-scope, dependent definites are, in effect, bound by a quantifier. The cases presented here constitute non-dependent definites, or if you like definites which are only "modally dependent."

${ }^{28}$ Greek bare plurals are strongly novel. See Condoravdi (1992).
} 
Definite NP's can also be associated with a non-accidental generalization reading, as in (37), which is another indication that they can be bound by the implicit generic quantifier.

(37) Ta meli aftou tou organismou den kapnizoun. the members this-GEN the-GEN club-GEN not smoke 'The members/Members of this club do not smoke.'

Moreover, as Newton (1979) and Mackridge (1985) have observed, the interpretation of definites depends on the aspectual marking of the verb. Consider the following quotation from Mackridge $(1985,114)$ with respect to examples like (38a) and (38b): "The perfective (referring as it does more to specific actions than does the imperfective) may distinguish a definite from an indefinite subject... The Greek sentences are distinguished by a difference in aspect, the English by the absence or presence of the definite article." More accurately, the generalization is that if the verb does not exclude an iterative interpretation for the eventuality, as in ( $38 \mathrm{c})$, there is an ambiguity between the quantificational reading, correlating with a habitual interpretation for the whole sentence, and the anaphoric reading, correlating with an iterative interpretation for the eventuality.
a. I kopeles pethanan noris. The girls died-PERF. early 'The girls died early.'

b. I kopeles pethenan noris. The girls died-MPERF. early 'Girls used to die early.'

c. I kopeles evgenan ekso. The girls went-IMPERF. out.

'The girls went out (repeatedly).' or 'Girls used to go out.'

What distinguishes (38a) from (38b) is that there is an implicit operator in (38b), signalled by the imperfective aspect on the verb, which binds the definite. In (38a) the definite receives its usual anaphoric reading since this is a regular episodic context. With an iterative interpretation for the imperfectively marked verb we again get the anaphoric reading for the NP since no operator is present. ${ }^{29}$

As a first attempt, we might say (along with Mackridge) that the definiteness marking on the NP is a superficial feature which should not lead us to

\footnotetext{
${ }^{29}$ The exact workings of aspect marking are far from straightforward but we can be sure that genericity or habituality requires imperfective aspect on the verb and that in episodic contexts we can bave either the perfective with a completive interpretation or the imperfective with an iterative interpetation.
} 
believe that such NP's are necessarily definite. In this vein, we may assume that in Greek we have two kinds of plural indefinites, an indefinitely marked indefinite and a definitely marked indefinite, and we can make provisions so that indefinitely marked indefinites are always in the domain of existential closure, say the VP or the focus domain, while definitely marked indefinites are always outside of that domain. This way, however, we cannot have an explanation for why definitely marked indefinites can never have a purely existential reading and for what differentiates definitely marked and indefinitely marked indefinites bound by a quantifier.

We are now in a good position, both conceptually and technically, to approach the issue from the opposite direction. That is, we can interpret definiteness in Greek in such a way that definites can be bound directly by quantifiers. From the perspective of the novelty/familiarity theory of definiteness and indefiniteness, this would amount to allowing the index of a definite to be novel so that quantification may work as in Heim's system, while at the same time requiring the familiarity of the descriptive content so as to make the definiteness marking non-arbitrary. The evidence that this is the right approach to take comes from the apparent free variation between definites and indefinites in modal contexts. Consider (39), where both the definite and the indefinite can be bound by the modal prepi.

a. Ta pedia me kolitikes arrosties prepi na benoun edo mesa. The children with infectious diseases must enter-suBJ here in 'The children/Children with infectious diseases must enter in here.'

b. Pedia me kolitikes arrosties prepi na benoun edo mesa. Children with infectious diseases must enter-suBJ here in 'Children with infectious diseases must enter in here.'

While both (39a) and (39b) may express a generalization over potential, not just actual, individuals, (39a) presupposes that all the worlds in the modal base of the deontic modal contain children with infectious diseases, whereas $(39 \mathrm{~b})$ is neutral on this score.

I propose that definites may be distinguished according to whether they are weakly or strongly familiar and that plural definite NP's in Greek are weakly familiar. A definite is WEAKLY PAMILIAR iff it is associated with a descriptive content condition. A definite is STRONGLY FAMILIAR iff it is associated both with an index and a descriptive content condition. The index condition specifies that the index must be in the domain of the file. The descriptive content condition states that a file $\mathrm{F}$ would be an admissible context for the addition of a definite NP only if it entails the file obtained by incrementing F with NP.

(40) $F_{1}=F+N P_{i}$, where $N P_{i}$ is weakly familiar, is defined only if $F$ entails $\mathrm{F}+\mathrm{NP}_{i}$ (i.e., for every $\left\langle\mathrm{a}_{N}, w>\in \mathrm{Sat}(\mathrm{F})\right.$ there is a $\mathrm{b}_{N}$ agreeing with a for all $j \in \operatorname{Dom}(\mathrm{F})$ such that $\left\langle\mathrm{b}_{N}, w>\in \operatorname{Sat}\left(\mathrm{F}+\mathrm{NP}_{i}\right)\right.$ ). 
(41) $\mathrm{F}_{1}=\mathrm{F}+\mathrm{NP}$, where $\mathrm{NP}_{i}$ is strongly familiar, is defined only if both (a) and (b) hold:

a. $i \in \operatorname{Dom}(\mathrm{F})$;

b. $\mathrm{F}$ entails $\mathrm{F}+\mathrm{NP}_{i}$ (i.e., for every $\left\langle\mathrm{a}_{N}, w\right\rangle \in \mathrm{Sat}(\mathrm{F})$ there is a $\mathrm{b}_{N}$ agreeing with $\mathrm{a}_{N}$ for all $j \in \operatorname{Dom}(\mathrm{F})$ such that $\left\langle\mathrm{b}_{N}, w\right\rangle \in \operatorname{Sat}\left(\mathrm{F}+\mathrm{NP}_{i}\right)$ ).

If $\mathrm{F}$ does not entail $\mathrm{F}+\mathrm{NP}_{i}$, then it does not entail $\mathrm{NP}_{i}$ but not vice versa; if $i \in \operatorname{Dom}(\mathrm{F})$ and $\mathrm{F}$ entails $\mathrm{F}+\mathrm{NP}_{i}$, then $\mathrm{F}$ entails $\mathrm{NP}_{i}$.

\section{Conclusion}

In this paper I have argued for a more fine-grained theory of novelty and familiarity and for not always tying both the index condition and the descriptive content condition to definiteness and indefiniteness, based on evidence that there are indefinites presupposing their descriptive content and definites with a novel index. Indefinite NP's always introduce a new discourse referent and definite NP's always presuppose existence.

The set of admissible contexts for weakly novel NP's properly includes the set of admissible contexts for strongly novel NP's and the set of admissible contexts for weakly familiar NP's properly includes the set of admissible contexts for strongly familiar NP's. Hence weakly novel NP's have the whole range of readings that strongly novel NP's do (plus more) and weakly familiar NP's have the whole range of readings that strongly familiar NP's do (plus more). If all indefinites are at least weakly novel, then the basic property shared by all indefinites must be that they are never anaphoric. If all definites are at least weakly familiar, then the basic property shared by all definites must be that they never assert existence.

\section{References}

Carlson, G. 1977. Reference to Kinds in English. Doctoral dissertation, University of Massachusetts, Amherst.

Chierchia, G. 1992. Anaphora and Dynamic Binding. Linguistics and Philosophy 15:111-183.

Condoravdi, C. 1992. Weakly and Strongly Novel Noun Phrases. Proceedings of the West Coast Conference in Formal Linguistics, vol. 11.

Cooper, R. 1979. The Interpretation of Pronouns, Syntax and Semantics 10, eds. F. Heny and H. Schnelle, 61-92. Academic Press, New York.

Dahl, Ö. 1975. On Generics. Formal Semantics of Natural Language, ed. E. Keenan, 99-111. Cambridge University Press.

Diesing, M. 1990. The Syntactic Roots of Semantic Partition. Doctoral dissertation, University of Massachusetts, Amherst.

Engdahl, E. 1986. Constituent Questions, Reidel, Dordrecht.

Gawron, M., J. Nerbonne, and S. Peters. 1991. The Absorption Principle and E-Type Anaphora. CSLI Report No. CSLI-91-153 RR-91-12. 
Heim, I. 1982. The Semantics of Definite and Indefinite Noun Phrases. Doctoral dissertation, University of Massachusetts, Amherst.

Heim, I. 1983. On the Projection Problem for Presuppositions. Proceedings of the West Coast Conference in Formal Linguistics, vol. 2, 114-125.

Heim, I. 1987. Where Does the Definiteness Restriction Apply? Evidence from the Definiteness of Variables. The Representation of $(I n)$ definiteness, eds. E. J. Reuland and A. G. B. ter Meulen, 21-42. MIT Press,

Heim, I. 1990. E-Type Pronouns and Donkey Anaphora. Linguistics and Philosophy 13:137-177.

Hintikka, J. 1986. The Semantics of A Certain. Linguistic Inquiry 17:331-336.

Kamp, H. 1981. A Theory of Truth and Semantic Representation. Formal Methods in the Study of Language, eds. J. Groenendijk, T. Janssen, and M. Stokhof, 277-321. Mathematisch Centrum, Amsterdam.

Karttunen, L. 1974. Presupposition and Linguistic Context. Theoretical Linguistics 1:181-194.

Kratzer, A. 1981. The Notional Category of Modality. Words, Worlds and Contexts - New Approaches in Word Semantics, eds. H.-J. Eikmeyer and H. Rieser, 38-74. Berlin: W. de Gruyter.

Kratzer, A. 1989. Stage-Level and Individual-Level Predicates. Manuscript, University of Massachusetts, Amherst.

Krifka, M. 1987. Syntax and Semantics of Definite and Indefinite Generics. Partly in collaboration with C. Gerstner. Manuscript, Universität Tübingen.

Krifka, M. 1988. The Relational Theory of Genericity, Genericity in Natural Language, ed. M. Krifka, 285-312. Seminar für Natürlich-Sprachliche Systeme der Universität Tübingen, SNS-Bericht 88-42.

Krifka, M. 1990. Genericity: An Introduction. Manuscript, University of Texas at Austin.

Mackridge, P. 1987. The Modern Greek Language. Oxford University Press.

Milsark, G, 1974. Existential Sentences in English, Doctoral dissertation, MIT.

Newton, B. 1979. Scenarios, Modality, and Verbal Aspect in Modern Greek. Language 55:139-167.

Wilkinson, K. 1988. Genericity and Indefinite NP's. Manuscript, University of Massachusetts, Amherst.

CSLI, Ventura Hall

Stanford University

Stanford, CA 94305

condorav@csli.stanford.edu 
